Portland State University

PDXScholar

\title{
Toward a Reliable Prediction of Seasonal Forecast Uncertainty: Addressing Model and Initial Condition Uncertainty with Ensemble Data Assimilation and Sequential Bayesian Combination
}

Caleb Matthew DeChant

Portland State University

Hamid Moradkhani

Portland State University

Follow this and additional works at: https://pdxscholar.library.pdx.edu/cengin_fac

Part of the Civil and Environmental Engineering Commons, and the Hydrology Commons Let us know how access to this document benefits you.

\section{Citation Details}

DeChant, C.M., Moradkhani, H., Toward a Reliable Prediction of Seasonal Forecast Uncertainty: Addressing Model and Initial Condition Uncertainty with Ensemble Data Assimilation and Sequential Bayesian Combination, Journal of Hydrology (2014), doi: http://dx.doi.org/10.101/j.jhydrol.2014.05.045

This Post-Print is brought to you for free and open access. It has been accepted for inclusion in Civil and Environmental Engineering Faculty Publications and Presentations by an authorized administrator of PDXScholar. Please contact us if we can make this document more accessible: pdxscholar@pdx.edu. 

context of seasonal hydrologic predictions, these uncertainties can be attributed to three causes:

12 imperfect characterization of initial conditions, an incomplete knowledge of future climate and 13 errors within computational models. This study proposes a method to account for all threes 14 sources of uncertainty, providing a framework to reduce uncertainty and accurately convey 15 persistent predictive uncertainty. In currently available forecast products, only a partial 16 accounting of uncertainty is performed, with the focus primarily on meteorological forcing. For 17 example, the Ensemble Streamflow Prediction (ESP) technique uses meteorological climatology to estimate total uncertainty, thus ignoring initial condition and modeling uncertainty. In order to 19 manage all three sources of uncertainty, this study combines ESP with Ensemble Data 20 Assimilation, to quantify initial condition uncertainty, and Sequential Bayesian Combination, to 21 quantify model errors. This gives a more complete description of seasonal hydrologic forecasting 22 uncertainty. Results from this experiment suggest that the proposed method increases the 23 reliability of probabilistic forecasts, particularly with respect to the tails of the predictive 24 distribution.

26 Keywords

27 Streamflow Forecasting, Data Assimilation, Multi-modeling, Ensemble Streamflow Prediction

\footnotetext{
${ }^{1}$ Corresponding author, hamidm@pdx.edu
} 


\section{Introduction}

Uncertainty is pervasive throughout hydrologic forecasting. A general lack of

30 information, and skillful modeling frameworks, leads to forecast products that do not have

31 sufficient ability to be relied upon in an entirely deterministic manner. In the specific case of

32 seasonal streamflow, volumetric estimates of runoff are necessary for guidance of an array of

33 water management decisions, yet the accuracy of such estimates is often unsatisfactory

34 (Moradkhani and Meier, 2010). To this end, it should be of high priority to ensure that estimates

35 of forecast uncertainty are statistically reliable. Given that probabilistic estimates of volumetric

36 streamflow are reliable, risk within a reservoir system can be more effectively managed, thus

37 reducing the chance of both flood damages and water shortages concurrently.

38 Research into probabilistic methods for seasonal forecasts has developed over the past

39 few decades. A first example is the Ensemble Streamflow Prediction (ESP) framework proposed

40 by Twedt et al., (1977) and clarified by Day (1985). ESP works under the assumption that the

41 primary skill in a hydrologic forecast is based on land surface conditions, and as such treats

42 initial conditions as deterministic quantities, while leveraging climatological stochastic forcing to

43 account for poor knowledge of future meteorological conditions. The framework itself has

44 prompted a number of studies to improve seasonal forecasting, including utilizing information

45 from climate indices (Najafi et al., 2012) and climate modeling products (Mo et al., 2013; Yuan

46 and Wood, 2012). Since the literature suggests that some information about seasonal climate is

47 available through both climate modeling and teleconnections, further studies have examined the

48 assumption that skill is primarily derived from initial conditions (Li et al., 2009; Shukla et al.,

49 2013; Wood and Schaake, 2008; Yossef et al., 2012). With an increasing focus on the relative 
50 skill of different aspects of seasonal forecasting, an increasing focus has been placed on

51 determining how best to manage overall uncertainty in the modeling framework.

52 Interest in probabilistic forecasting is increasing within the hydro-meteorological

53 research and operational communities (Brown et al., 2010; Demargne et al., 2013; Madadgar et

54 al., 2012; Yuan et al., 2013), yet forecast systems rarely approach the uncertainty estimation

55 problem holistically. Primarily, in the seasonal streamflow forecasting realm, these uncertainties

56 arise from meteorological forcing of the model, initial land surface conditions, and model

57 uncertainty. The forecasting community has understandably focused predominantly on the

58 uncertainties relative to future weather conditions, as these uncertainties will become dominant

59 at most forecast lead times (Shukla et al., 2013; Yossef et al., 2012). More specifically, the

60 forecast steadily loses sensitivity to the initial conditions over time, but the forecast will remain

61 sensitive to forcing at all lead times. Though such methods lead to probabilistic flow estimates,

62 these methods generally underestimate the forecasting uncertainty (Wood and Schaake, 2008,

63 Yuan and Wood, 2012). The objective of this study is to develop and test a technique to improve

64 the quantification of uncertainty in probabilistic forecasting of seasonal volumetric streamflow,

65 thus reducing the problem of overconfidence. In order to overcome this overconfidence, this

66 study proposes a movement towards treating the initial land surface states and models as

67 probabilistic values, in addition to meteorological forcing.

Probabilistic estimation of land surface states has proven to be a challenge throughout the

69 land surface modeling community, but great strides are being made in the field of ensemble data

70 assimilation (DA) (Moradkhani, 2008). A number of researchers have been looking into the use

71 of DA methods for improving land surface state prediction (Andreadis and Lettenmaier, 2006;

72 Clark et al., 2008; De Lannoy et al., 2012; Margulis et al., 2002; Reichle et al., 2002) and 
examining the ability of stochastic states to estimate uncertainty reliably (DeChant and

74 Moradkhani, 2011a; Leisenring and Moradkhani, 2010; Liu and Gupta, 2007; Moradkhani et al.,

75 2005a,b). The extensive literature on ensemble DA within hydrologic models motivated the use

76 of ensemble DA techniques for probabilistic initial state estimation (ESP-DA) as presented in

77 DeChant and Moradkhani (2011b). Results from this study suggested that accounting for initial

78 condition uncertainty in ESP improves the reliability of seasonal streamflow forecasting, but that

79 results remain overconfident. An important issue that potentially causes this persistent

80 overconfidence is the assumption that model uncertainty is insignificant. Thus model error must

81 also be examined in a seasonal forecasting framework.

An increasingly popular method to account for model uncertainty is through multi-model

83 ensembles (Bohn et al., 2010; Regonda et al., 2006). By having a diverse set of models, a

84 forecast implicitly accounts for the errors related to each individual model. Multi-modeling via

85 Bayesian Model Averaging (BMA) is becoming an increasingly popular technique throughout

86 hydrologic forecasting (Ajami et al., 2007; Duan et al., 2007; Raftery et al., 2005), which has

87 also been extended to estimate the posterior model probability sequentially in time, which is

88 referred to as Sequential Bayesian Combination (SBC) (Hsu et al., 2009). Recently, both BMA

89 and SBC have been shown to be completely compatible with ensemble DA (Parrish et al., 2012),

90 leading the current study to propose the use of model averaging within the previously developed

91 ESP-DA framework to simultaneously account for initial condition and model uncertainty.

92 Through these advancements, it is possible to move hydrologic forecasting towards a more

93 complete accounting of uncertainty (Liu et al., 2012). Thus the hypothesis of this study is that

94 ESP with DA and SBC will lead to more reliable probabilistic forecasts of seasonal streamflow,

95 in comparison to traditional ESP, and the previously examined ESP-DA methodology. 


\section{Methods}

\subsection{Study Area}

The study examines streamflow forecasting throughout the Upper Colorado River Basin (UCRB), defined here as the entire Colorado River Basin upstream of Lee's Ferry (see Figure 1), which is located just downstream of Lake Powell. The UCRB is located in the southwestern US, covering portions of Wyoming, Utah, Colorado, Arizona and New Mexico. The basin drains an area of roughly $280,000 \mathrm{~km}^{2}$, with forest covering much of the upper elevations and shrub land covering the valleys. The mean naturalized yearly flow volume at Lee's Ferry is roughly 18 billion cubic meters, providing water to 26 million people with a minimum designated annual flow from Lake Powell set at 9.3 billion cubic meters. In Figure 1, the gauges of the three major sub-basins (Green River, Colorado Headwaters/Gunnison and San Juan) and at Lee's Ferry are identified. These four gauges are used to examine overall forecast reliability, whereas spatial aspects of forecast accuracy are analyzed over 16 smaller sub-basins.

\subsection{Hydrologic Models}

\subsubsection{Variable Infiltration Capacity Model}

The VIC model is a physically-based, distributed model that solves the energy and water balance at the land surface, and spatially discretized units are generally placed on a regular grid (Gao et al., 2010; Liang et al., 1994). In order to perform model calculations, VIC requires soil information, vegetation information, elevation bands, precipitation, maximum and minimum temperature, average wind speed, humidity, and incoming shortwave and longwave radiation for each grid cell. Land surface parameters for VIC simulations were gathered from the Natural Resources Conservation Services STATSGO dataset (soil) and the University of Maryland land cover dataset (vegetation). Elevation bands were defined using the USGS National Elevation 
119 Dataset, with information from the Precipitation Regression on Independent Slopes Model

120 (PRISM) yearly precipitation information to aid in the distribution of elevation band

121 precipitation. Readers are referred to section 2.5 for information about the forcing data.

122 Simulations were performed over the entire UCRB at a spatial resolution of $0.25^{\circ}$, which makes

123473 model grid cells. Based on the hydrologic fluxes estimated by VIC, excess water is routed to

124 the outlet of the basin with a combination of Nash-Cascade hydrologic routing and Muskingum-

125 Cunge hydraulic routing.

\subsubsection{National Weather Service River Forecast Center Models}

The SNOW-17 and Sacramento Soil Moisture Accounting (SAC-SMA) models are used

128 by the National Weather Service (NWS) to provide operational streamflow forecasts for flood 129 and water supply monitoring. These models are coupled, with SNOW-17 handling snow 130 accumulation/ablation calculations and SAC-SMA modeling the soil water storage component.

131 Both SNOW-17 and SAC-SMA have a more conceptual nature to model equations than VIC, 132 leading to an increased reliance on calibration, as opposed to soil and vegetation data. 133 Fortunately, the NWS calibrated parameters for each basin within the UCRB have been made 134 available by the Colorado Basin River Forecast Center (CBRFC). The NWS performs 135 simulations from these models with elevation bands for each sub-basin, leading to 409 136 discretized units. To run SNOW-17 and SAC-SMA, precipitation, average temperature, and 137 potential evapotranspiration (PET) are required. Excess runoff from these models is routed to the 138 outlet with a unit hydrograph for hydrologic routing and Lag/K for hydraulic routing. 


\subsection{Observations}

\subsubsection{Passive Microwave Radiance}

Passive Microwave (PM) brightness temperature $\left(\mathrm{T}_{\mathrm{b}}\right)$ from the Advanced Microwave Scanning Radiometer - Earth Observing System (AMSR-E) data was used in this study to perform land surface DA. $\mathrm{T}_{\mathrm{b}}$ was chosen for this study as it provides useful information about water stored at the land surface due to its sensitivity to snow water equivalent (SWE) (18.7 and 36.5GHz AMSR-E channels) and soil moisture (6.9 GHz AMSR-E channel). With its sensitivity to both soil moisture and SWE, PM observations provide valuable information about the water storage immediately above and below the land surface. In the presence of snow cover, microwave radiation is a function of snow depth, density, temperature, grain size, and liquid water content (Weismann and Mätzler 1999), and is a function of soil type, temperature and liquid water content in the case of bare soil (Drusch et al., 2001). In order to assimilate $\mathrm{T}_{\mathrm{b}}$, a radiative transfer model (RTM) is used to calculate the microwave radiance from the land/snow surface (Durand and Margulis, 2008; DeChant and Moradkhani, 2011; Montzka et al., 2012, 2013; Andreadis and Lettenmaier, 2012). The RTMs used in this study are described in section 2.4. Passive microwave observations were gathered from the AMSR-E L2A dataset, which was recently shown to have greater information content, with respect to SWE, than the spatially and temporally resampled EASE-Grid products (Li et al., 2012), and distributed to the centroid of each discretized modeling unit through inverse distance squared weighting.

\subsubsection{Land Surface Temperature}

Land surface temperature (LST) data from the Moderate Resolution Imaging Spectroradiometer (MODIS) were assimilated in conjunction with PM $\mathrm{T}_{\mathrm{b}}$ to improve model estimation of surface temperature, and therefore provide more accurate energy balance 
162 estimation and simulations from the RTMs. LST from MODIS is particularly attractive for this

163 study because of the fine resolution observations (1 km by $1 \mathrm{~km}$ ) and the high frequency (up to 4

164 observations every 24 hours) of measurements, due to its deployment on both the NASA Aqua 165 and Terra satellites. With high frequency and resolution of the observations, MODIS LST is a 166 powerful source of information about the land surface energy balance. LST from MODIS is 167 estimated through the Generalized Split-Window Algorithm (Wan and Dozier, 1996). This uses 168 the difference between MODIS bands 31 and 32, along with estimated land surface emissivity, to 169 estimate the true temperature of the land surface (Wan and Dozier 1996; Wan et al., 2004). In 170 this study, MODIS LST is aggregated to model resolutions with spatial averaging of 171 observations within each discretized unit.

\subsubsection{Naturalized Flow}

173 Naturalized flow data for the UCRB is provided by the United States Bureau of

174 Reclamation (USDOI, 2005). This dataset contains flow reconstructions throughout the entire

175 Colorado Basin, with 20 reconstruction locations in the upper region. Flows are in the form of 176 monthly volumes. For the sake of this study, 16 different flow locations were chosen for

177 verification. In addition, the VIC model was optimized based on the mean square error of 178 monthly flow simulations, for the 10 years prior to the study period, at four locations: the Green 179 River at Green River, Utah, the Colorado River at Cisco, Utah, the San Juan at Bluff, Utah, and 180 Lees Ferry, Arizona, which are shown in Figure 1.

\subsection{Radiative Transfer Models}

Microwave emission from the land surface is modeled through a combination of the L-

183 Band Microwave Emission Model from the Biosphere (L-MEB) model (Wigneron et al., 2007),

184 for the case of bare soil, the Microwave Emission Model for Layered Snowpack (MEMLS) 
185 (Weismann and Mätzler 1999), when snow cover is present, and vegetation is modeled according

186 to Pullainen et al. (1998). Soil parameters required by the L-MEB model were estimated from

187 the STATSGO dataset, according to suggestions in Wigneron et al. (2007). Although these

188 parameters may be improved through sensitivity analysis (Sabater et al., 2011), calibration (De

189 Llannoy et al., 2013; Drusch et al., 2009) and even the data assimilation itself (Montzka et al.,

190 2013), the default parameters are preferred here to keep the focus on the proposed forecasting

191 technique. In addition to land surface parameters, atmospheric effects are accounted for as

192 described in Durand and Margulis (2008), which allows for comparison with AMSR-E

193 observations. In the VIC model, snow is represented with two layers, a small upper layer and a

194 larger deep layer, whereas SNOW-17 assumes a homogenous snowpack. Both models estimate

195 all snow variables necessary, with the exception of grain size, which is modeled according to

196 DeChant and Moradkhani (2011a). Microwave emission in the 6.9GHz frequency is ignored in

197 the NWS model as the SAC-SMA model does not estimate physical soil moisture. Within the

198 VIC model, assimilation of the $6.9 \mathrm{GHz}$ channel is motivated as the soil moisture is expected to

199 affect the forecast for up to one month lead time (Shukla et al., 2013). While SWE is expected to

200 be a much larger factor in the seasonal runoff, the soil moisture is expected to have significant

201 impact on seasonal volumetric runoff.

\subsection{Forcing Data}

203 Forcing datasets required for the VIC model are precipitation, maximum and minimum

204 temperature, potential evapotranspiration, wind speed, humidity, and incoming shortwave and 205 longwave radiation. Observed precipitation and temperature data was gathered from the NWS 206 Cooperative Observer Program (COOP) and NRCS SNOTEL sites, and then spatially distributed 207 over the VIC model cells. Distribution of precipitation and temperature was performed with 
208 scaling based on PRISM monthly data (Daly et al., 1994). Wind observations were gathered

209 from the NCEP/NCAR reanalsysis dataset (Kalnay et al., 1996), and then scaled to the modeling

210 domain, following the method of Mauer et al., (2002). Humidity is estimated according to

211 Kimball et al., (1997), shortwave radiation is estimated according to Thornton and Running,

212 (1999), and longwave radiation is estimated according to Bras, (1990), all of which are

213 performed internally in the VIC model. The NWS models require precipitation, temperature and

214 PET. All forcing for these models was provided by the CBRFC, where precipitation and

215 temperature are estimated from in-situ observations, and PET is estimated based on pan

216 evaporation rates.

$217 \quad 2.6 \quad$ Error Models

218 Stochastic estimates of precipitation, temperature, wind, and PET were used to drive the

219 hydrologic models. Precipitation errors are assumed to be heteroschedastic and log-normal with

220 a variance of $25 \%$ of the magnitude, temperature errors (PM T, LST and Air Temperature) are

221 assumed to be homoschedastic and normal with a standard deviation of $3^{\circ} \mathrm{C}$, and both PET and

222 Wind are assumed to have a heteroschedastic normal error with variance equal to $25 \%$ of the

223 magnitude. The form and magnitude of these errors follow previous studies (DeChant and

224 Moradkhani 2011a,b, 2012; Parrish et al., 2012). In addition, this study also utilizes spatially and

225 temporally correlated errors as described by Clark and Slater (2006). For application of this

226 method, a correlation length of $100 \mathrm{~km}$ and temporal correlation of 5 days was used for all inputs,

227 similar to the application in Clark et al. (2008). 


\section{Experimental Design}

\subsection{Particle Filtering and Sequential Bayesian Combination}

Within a DA framework, the hydrologic model is viewed through the state-space

231 framework as shown in equations (1) and (2).

$232 x_{i, t}^{-}=f\left(x_{i, t-1}^{+}, u_{i, t}, \theta\right)$

$233 y_{i, t}^{\prime}=h\left(x_{i, t}^{-}, \alpha\right)+v_{i, t}$

234 In the above equations, the $i^{\text {th }}$ prior states $\left(x_{i, t}^{-}\right)$are estimated through the propagation of the

235 model forward in time, from the $i^{\text {th }}$ posterior states at the previous time step $\left(x_{i, t-1}^{+}\right)$, utilizing

236 stochastic forcing data $\left(u_{i, t}\right)$ and static simulation model parameters $(\theta)$. Note that model error

237 not added to the states estimated from equation (1), which differs from common representations.

238 The exclusion of model error at this stage is chosen to avoid altering the physical relationship

239 between snow states, which has been found to degrade SWE reconstruction through AMSR-E

240 data assimilation (DeChant and Moradkhani, 2011a). When this error is included, the

241 relationship between snow states (i.e. depth, density, liquid water content, temperature, grain

242 size) is damaged, which leads to errors in future simulations of both the RTM and snow model.

243 From the prior states and static observation model parameters $(\alpha)$, the prediction of the

244 streamflow, LST and $\mathrm{T}_{\mathrm{b}}\left(y_{i, t}^{\prime}\right)$ is created with the evaluation of an observation operator $(h(\bullet))$

245 with some predictive error $\left(v_{i, t}\right)$. For applying DA, the Particle Filter $(\mathrm{PF})$ is utilized in the study

246 presented here. The PF follows sequential Bayes Law (equation 3) to estimate the posterior state 247 distribution. 
$248 p\left(x_{t} \mid y_{1: t}\right)=\frac{p\left(y_{t} \mid x_{t}\right) p\left(x_{t} \mid y_{1: t-1}\right)}{\int p\left(y_{t} \mid x_{t}\right) p\left(x_{t} \mid y_{1: t-1}\right) d x}$

249 Equation 3 mathematically describes the development of a posterior distribution of model

250 predicted states, given all past observations $\left(y_{1: t}\right)$, by calculating probabilities sequentially in

251 time. Sequential Bayes Law states that the posterior is estimated by the normalized product of

252 the prior distribution, $p\left(x_{t} \mid y_{1: t-1}\right)$, and the likelihood, $p\left(y_{t} \mid x_{t}\right)$. In this study, the prior

253 distribution is estimated as the importance density estimated in equation (1), and the likelihood is

254 Gaussian, which is calculated based on the residuals observed and simulated (from equation (2))

255 PM $\mathrm{T}_{\mathrm{b}}$. This provides a weighted ensemble of states, which represents the posterior distribution.

256 Due to the potential for ensemble members to attain insignificant weight, states are resampled at

257 every observation time step, via the Sampling Importance Resampling (SIR) technique, to

258 develop a probability density with uniform weights. For further details on the implementation of

259 the PF, see Moradkhani and Sorooshian (2008).

260 Research into streamflow estimation with DA has also highlighted the benefits of

261 parameter estimation for quantifying forecast uncertainty (DeChant and Moradkhani, 2012). This

262 methodology has been rapidly advancing, which has potential for improving uncertainty in

263 streamflow forecasting. Specifically, Moradkhani et al., (2012) introduced a method of

264 parameter estimation using the Variable Variance Multiplier (VVM) (Leisenring and

265 Moradkhani, 2012) methodology for generating proposal parameters, and Metropolis acceptance

266 criteria to ensure that parameters remain within the meaningful regions of the posterior

267 distribution. Through this methodology, parameter estimates are more robust than with

268 previously used PFs. Although parameter estimation is a potential avenue for improving 
269

270

271

272

273

274 varying model behavior represents uncertainty. The theory behind this method is described

275 briefly in equation (4) and (5), but the reader is referred to previous applications for additional

276 details.

277

$$
p\left(M_{k} \mid D\right)=\frac{p\left(D \mid M_{k}\right) p\left(M_{k}\right)}{p(D)}
$$

$$
p\left(y^{\prime} \mid M_{1: K}, D\right)=\sum_{k=1}^{K} p\left(y^{\prime} \mid M_{k}, D\right) p\left(M_{k} \mid D\right)
$$

279

280 In equation (4), $M_{k}$ represents the $k^{\text {th }}$ model, $D$ is the training data, $p\left(M_{k} \mid D\right)$ is the posterior 281 model probability and $p\left(y^{\prime} \mid M_{1: K}, D\right)$ is the probability of the model prediction based on all $K$ 282 models. In this study, the SBC approach proposed by Hsu et al. (2009) is utilized to weight all 283 models. In this approach, model weights are calculated sequentially, similar to the PF, as shown 284 in equation (6).

$285 p\left(M_{k} \mid y_{1: t}\right)=\frac{p\left(y_{t} \mid M_{k}\right) p\left(M_{k} \mid y_{1: t-1}\right)}{\int p\left(y_{t} \mid M_{k}\right) p\left(M_{k} \mid y_{1: t-1}\right) d M}$

286 In equation (6), the prior distribution $\left(p\left(M_{k} \mid y_{1: t-1}\right)\right)$ is equal to the posterior probability at the

287 previous time step, and the likelihood $\left(p\left(y_{t} \mid M_{k}\right)\right)$ is estimated with a kernel density smoother 288 (Wilks, 2006) of the ensemble streamflow estimate from the PF. Parrish et al., (2012) recently showed that the PF and SBC are completely compatible, 290 and often advantageous when used in conjunction. Instead of making the assumption that model 291 errors are normally distributed, as is typically done in SBC and BMA, the PF can be utilized to 
292 develop a probabilistic prediction that is not bound by distributional parameters. Further, the

293 SBC method is preferred over non-Bayesian model averaging methods (Diks and Vrugt, 2010) to

294 remain consistent with the theoretical framework of the PF. With the posterior distribution from

295 filtering of each model, $p\left(y_{t}^{\prime} \mid M_{k}, y_{1: t}\right)$, and the weights of each model, $p\left(M_{k} \mid y_{1: t}\right)$, a probability

296 distribution of forecasts from all models can be estimated according to equation (7). In the

297 application here, each model probability is estimated based on the volumetric monthly flows

298 described in section 2.4.1. This is assumed to be a reasonable weighting scheme for the seasonal

299 volumetric flow forecasts analyzed here, but the effects the weighting time scale should be

300 addressed when moving to different forecast lead times (e.g. weekly or annual forecasts).

$301 p\left(y_{t}^{\prime} \mid M_{1: K}, y_{1: t}\right)=\sum_{i=k}^{K} p\left(y_{t}^{\prime} \mid M_{k}, y_{1: t}\right) p\left(M_{k} \mid y_{1: t}\right)$

$302 \quad 3.2$ Ensemble Streamflow Prediction with PF-SBC

303 ESP is a method used by the National Weather Service River Forecast System to create

304 probabilistic forecasts of seasonal streamflow volumes. This method leverages stochastic

305 meteorological data to generate a Monte Carlo sample of streamflow predictions to represent the

306 uncertainty of future streamflow estimates. As described in equation (8), the ESP technique

307 creates a density of streamflow simulations over the forecast period, with each individual

308 simulation referred to as a "trace", generated from the deterministic states, $x_{t}$, resampled

309 historical forcing, $u_{1: Y-1, t}$ ( $Y$ represents the current year), and some hydrologic model $M$, from

310 the initial forecast time $t$, to estimate the probability of forecast, where $\tilde{y}_{t}$ refers to forecasted

311 seasonal flow volumes, as opposed to $y_{i, t}^{\prime}$, which are the predictions during the spin-up period.

$312 p\left(\tilde{y}_{t} \mid x_{t}, u_{1: Y-1}, M\right)=\sum_{y=1}^{Y-1} p\left(\tilde{y}_{t} \mid x_{t}, u_{y, t}, M\right) \approx \sum_{y=1}^{Y-1} \delta\left(\tilde{y}_{t}-M\left(x_{t}, u_{y, t}, \theta, \alpha\right)\right) w_{y, t}$ 
313 Where $\delta$ is the Dirac delta function, $M\left(x_{t}, u_{y, t}, \theta, \alpha\right)$ represents the combined hydrologic

314 model $(f)$ and routing function $(h)$, which forecasts streamflow, following the description in

315 section 3.1, and $w_{y, t}$ is the weight of each trace at initial forecast time $t$, which is uniformly set to

$316 \frac{1}{Y-1}$. While the common practice is to give each trace equal weight, these weights may be

317 estimated with additional climate information (Najafi et al., 2012).

318 Initial model states are produced by running the model with observed input data up to the

319 initial forecast time-step, which is referred to as a "spin-up". Starting at this point, the model is

320 forced with resampled historical forcing $\left(u_{1: Y-1, t}\right)$, beginning at the initial forecast date, for each

321 historical observation year, to estimate meteorological climatology, thus producing a stochastic

322 streamflow forecast. By generating a stochastic streamflow forecast through ESP, it is assumed

323 that the initial state estimates are perfect, the resampled historical forcing represents the future

324 uncertainty, which inherently assumes climate stationarity, and the model has no error. Given

325 that the assumptions of climate stationarity, accurate model initial state estimates and accurate

326 model structure are not significantly violated, ESP will provide a reliable probabilistic prediction

327 of seasonal streamflow.

328 In any real application of ESP, the assumptions of perfect initial states and model

329 simulations will be violated, necessitating a methodology to account for errors in the states and

330 model, which is performed here with a combination of the PF and SBC (referred to here as PF-

331 SBC). Application of PF-SBC to the ESP framework requires two steps, which are outlined in

332 Figure 2. First, DA is performed in each model during the spin-up period to produce stochastic

333 initial states at each initial forecast date $\left(x_{1: N, t}\right)$, following the application by DeChant and 
334 Moradkhani (2011b). This ensemble of land surface states represents the uncertainty at the

335 initial forecast date, and a resulting distribution of streamflow forecasts from these states is

336 shown in equation (9), where $p\left(x_{i, t} \mid y_{1: t}\right)$ is the posterior distribution from the PF and the weights

$337 w_{i, t}$ are uniform due to the application of SIR. This is the single model ESP-DA forecast.

338

$p\left(\tilde{y}_{t} \mid x_{1: N, t}, u_{1: Y-1}, M, y_{1: t}\right)=\sum_{y=1}^{Y-1} \sum_{i=1}^{N} p\left(\tilde{y}_{t} \mid x_{i, t}, u_{y, t}, M\right) p\left(x_{i, t} \mid y_{1: t}\right)$

$\approx \sum_{y=1}^{Y-1} \sum_{i=1}^{N} \delta\left(\tilde{y}_{t}-M\left(x_{i, t}, u_{y, t}, \theta, \alpha\right)\right) w_{y, t} w_{i, t}$

339 A second step is performing the ESP-DA with all models, and then applying the weights to each

340 ensemble member. In this step, each model and initial state ensemble member is propagated

341 forward with the ESP framework, providing a multi-model ensemble forecast, creating

$342 N *(Y-1) * K$ streamflow traces. At this point, a stochastic multi-model forecast is available,

343 represented by $p\left(\tilde{y}_{t} \mid x_{1: N, t}, u_{1: Y-1}, M_{1: K}\right)$, but this does not account for the relative accuracy of each

344 model, thus creating an overly uncertain forecast. In order to reduce this uncertainty, each model

345 is averaged according to PF-SBC, based on weights estimated from the observations during the

346 spin up period $\left(y_{1: t}\right)$. The proposed methodology estimates the probability distribution of $\tilde{y}_{t}$

347 based on resampled historical forcing, stochastic states and multiple weighted models, as

348 represented in equation (10). In the application presented here, both $w_{i, t}$ and $w_{y, t}$ are uniform,

349 and therefore their product is equal to $1 /(N *(Y-1))$, making the weight of each trace estimated

350 by equation (11). Although this study produces a weighted ensemble, a uniformly weighted

351 ensemble forecast may be preferred in operational applications to be more consistent with the

352 conventional ESP methodology. In order to overcome this issue, forecast ensemble members

353 may be resampled, similar to the SIR, therefore producing an ensemble forecast with equally 
354 weighted members. Note that this resampling of ensemble forecasts was not performed here, but

355 such a discussion is provided to explain the potential use in an operational setting.

356

$p\left(\tilde{y}_{t} \mid x_{1: N, t}, u_{1: Y-1}, M_{1: K}, y_{1: t}\right)=\sum_{y=1}^{Y-1} \sum_{i=1}^{N} \sum_{k=1}^{K} p\left(\tilde{y}_{t} \mid x_{i, t}, u_{y}, M_{k}\right) p\left(M_{k} \mid y_{1: t}\right) p\left(x_{i, t} \mid y_{1: t}\right)$

$\approx \sum_{y=1}^{Y-1} \sum_{i=1}^{N} \sum_{k=1}^{K} \delta\left(\tilde{y}_{t}-M_{k}\left(x_{i, t}, u_{y, t}, \theta, \alpha\right)\right) w_{y, t} w_{i, t} w_{k, t}$

$w_{k, i, y, t}=w_{y, t} w_{i, t} w_{k, t}=\frac{1}{N *(Y-1)} p\left(M_{k} \mid y_{1: t}\right)$

\subsection{Performance Metrics}

The proposed forecasting framework is intended to improve the reliability of probabilistic

seasonal streamflow forecasts, as currently available techniques are typically overconfident. In

order to test the proposed methodology, this study requires the use of probabilistic verification

methods that quantify the reliability. Many techniques are available for probabilistic verification,

363 with the most commonly used methods in hydro-meteorological forecasting being the Brier

364 Score (binary or categorical events) or the Continuous Rank Probability Score (continuous

365 predictands), for quantitative assessment, and the Rank Histogram for visual assessment (Wilks,

366 2006; Jolliffe and Stephenson, 2003). Although the quantitative methods are commonly used,

367 they are not necessarily prudent in this application. Since the focus here is solely on forecast

368 reliability, and the Brier Score and Continuous Rank Probability Score both have aspects of

369 reliability, resolution, uncertainty and sharpness (Murphy, 1973; Hersbach, 2000), other

370 quantitative metrics are preferred.

The first quantitative measure is the Exceedance Ratio (ER) (Moradkhani et al., 2006;

372 Moradkhani and Meskele, 2009). This measure can be applied to any predictive quantile range

373 desired, but here it is used to analyze the tails of the distribution (99\%, 95\% and 90\%). 
374 Calculation of the ER of a given quantile range is performed according to equations (12), (13),

375 and (14). In these equations, the cumulative probability of each observation, given its respective

376 forecast, is represented by $z_{t}$. This vector $z$ can then be analyzed at any predictive bound $P$

377 desired, as shown in equation (13). Then the ER is estimated as the percentage of observations

378 that fall outside this quantile range, which should be equal to $1-P$. Since the ER is used to

379 examine the tails of the distribution, a metric is also necessary to examine the whole probabilistic

380 forecast. The reliability $(R)$ is used here to examine the entire predictive distribution. This

381 measure is based on the assumption that over a large enough sample of observations, the

382 probabilities of those observations given their respective probabilistic forecast $\left(p\left(y_{t} \mid y_{1: N, t}^{\prime}\right)\right)$

383 will be uniformly distributed, which indicates that each quantile contains the statistically correct

384 portion of observations (e.g. $50 \%$ of the observations fall within the interquartile range). This is

385 described in equations (12), (15), and (16). Similar to the ER, a vector $z$ is calculated, but here

386 they are sorted in ascending order, as noted in equation (15). The reliability can then be

387 calculated according to equation (16), where the $\hat{z}$ are compared against the uniform cumulative

388 density to determine the accuracy of the probabilistic forecast. A value of 1 equals a perfect

389 forecast and a value of 0 is the mathematically worst forecast.

390

$z_{t}=\sum_{k=1}^{K} \sum_{i=1}^{N} \sum_{y=1}^{Y-1} \chi_{k, i, y, t} \quad \chi_{k, i, y, t}=\left\{\begin{array}{cc}w_{k, i, y, t} & y_{t}>\tilde{y}_{k, i, y, t} \\ 0 & y_{t}<\tilde{y}_{k, i, y, t}\end{array}\right.$

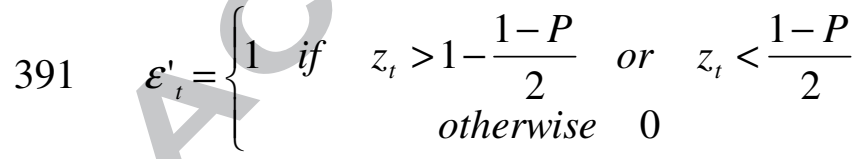

$392 E R=100 \times \sum_{t=1}^{T} \frac{\varepsilon_{t}^{\prime}}{T}$

$393 \hat{z}=\operatorname{sort}\left(z_{1: t}\right)$ 
$394 \quad R=1-2 \sum_{t=1}^{T}\left|\hat{z}_{t}-\frac{t}{T}\right|$

The predictive Quantile-Quantile (QQ) plot is used as a visual method to diagnose errors

396 in the forecast distribution (DeChant and Moradkhani, 2011b). This diagram presents nearly

397 identical information to the more commonly used Rank Histogram, but the predictive QQ plot is

398 preferred here, as multiple forecasts may be evaluated on the same plot. This plot compares the

$399 \hat{z}$ vector on the $\mathrm{x}$-axis and the uniform distribution on the $\mathrm{y}$-axis to examine the reliability of the

400 forecast distribution. Given that the plot follows a 1:1 line, this forecast is perfectly reliable

$401(R=1)$. If the predictive QQ line falls above the 1:1 line, the forecast has a high bias (observations

402 have a tendency to fall too low in the forecast distribution) and a predictive QQ line falling

403 below the 1:1 line indicates a low bias. In addition to bias, the over/underconfidence of a forecast

404 distribution can be diagnosed with this plot. If the predictive QQ line falls above the left side of

405 the 1:1 line and crosses the 1:1 line in the middle, the forecast is overconfident (a

406 disproportionately high number of observations being captured by the outer quantiles) and the

407 reverse indicates underconfidence. For a more complete explanation of this plot, see Laio and

408 Tamea (2007).

\subsection{Experiments}

410 In this study, seasonal ensemble forecasts are examined from seven different modeling

411 scenarios. The first two forecast experiments are the standard ESP method, referred to as "open

412 loop". The first open loop experiment is performed with the NWS models, and the second open

413 loop experiment is performed with the VIC model. Each open loop experiment performs a spin

414 up to an initial forecast date, and then 29 separate forcing years are resampled between 1981 and

4152010 to represent climatology (the forecast year is excluded leaving only 29 of the 30 years 
416 used). Four more experiments are performed with DA as a spin up. Each model (VIC and NWS)

417 has a spin up with $\mathrm{T}_{\mathrm{b}}$ only and $\mathrm{T}_{\mathrm{b}} / \mathrm{LST}$ DA. Each DA experiment uses 100 ensemble members,

418 leading to 100 initial condition estimates at each forecast time step, from October $1^{\text {st }}, 2002$

419 through September $30^{\text {th }}$, 2008. Within the PF-SBC algorithm, all streamflow observations are

420 utilized for model weighting, up to the initial forecast date, which makes the minimum length of

421 training data 3 months, and is deemed reasonable based on the findings in Parrish et al., (2012).

422 In the VIC model, it is infeasible to perform all 2900 combinations of initial condition ensemble

423 members and historical forcing years due to computational constraints, and therefore 500

424 combinations were sampled uniformly from those 2900. Computational demand in the NWS

425 models is significantly lower, and therefore all 2900 combinations are performed. The final

426 experiment is a model averaging experiment of all 6 prior modeling scenarios. All traces are

427 weighted according to the equations in section 3.2 and Figure 2, and the weighted ensemble is

428 evaluated. Each forecasting experiment estimates 3 month volumetric flow from start dates on

429 the $1^{\text {st }}$ and $15^{\text {th }}$ of January through June, in the years 2003 through 2008 . This leads to a total of

43072 seasonal forecasts from each modeling scenario.

4314 Results

432 A first assessment of the results from this study is provided with the weights of each

433 model in Figure 3. This figure shows the average model weights from each forecast month, as

434 estimated through the PF-SBC algorithm. In general, the NWS models appear to have the highest

435 weights, indicating a higher accuracy in monthly probabilistic streamflow volume estimation,

436 and more reliable estimation of streamflow uncertainty, than the VIC model. However, the VIC

437 model cases were assigned high enough weights to provide a significant contribution in the

438 model averaging framework. In comparing the DA and open loop cases, both DA cases in the 
439 NWS models received higher weight than the open loop model, yet the VIC model with DA

440 received an overall lower weight than the open loop case. A general expectation is for the VIC

441 model, which explicitly solves the energy balance, to be more effective in estimating inputs to

442 the radiative transfer model and land surface temperature, yet the application here does not

443 support this hypothesis. Although the results suggest VIC is less effective for $\mathrm{T}_{\mathrm{b}}$ and LST DA

444 than the NWS models, this is not a conclusion that should be drawn here due to the differing 445 spatial discretization and calibration schemes. Another important note is the difference in

446 performance of the two DA cases for each model. In the VIC model, the case of combined LST 447 and $\mathrm{T}_{\mathrm{b}} \mathrm{DA}$ outperforms the $\mathrm{T}_{\mathrm{b}}$ only DA case, but the NWS models perform best without the DA 448 of LST. This is not surprising, as the VIC model explicitly solves for LST, whereas the SNOW44917 model only estimates average pack temperature, thus the VIC model should more accurately 450 estimate LST. Figure 3 also highlights an import temporal aspect to the performance of these 451 modeling cases. In the DA cases, weights tend to be highest during the snow accumulation 452 season (January, February, and March) and have lower weights into the ablation season (May, 453 June). The reverse is true for the open loop cases. This finding is not surprising, due to the poorer 454 sensitivity of microwave $\mathrm{T}_{\mathrm{b}}$ to $\mathrm{SWE}$ in deeper snowpacks with high liquid water content 455 (DeChant and Moradkhani, 2011a). During the ablation season, the liquid water content in the 456 snowpack remains high, reducing the ability of $\mathrm{T}_{\mathrm{b}} \mathrm{DA}$ to accurately construct SWE. Such 457 temporal variation in DA performance necessitates the use of the PF-SBC methodology, as 458 opposed to batch framework, to allow for dynamic weights, thus providing more accurate 459 weights at each forecast initial condition.

460 During the forecast phase, the ability of each modeling case to reliably estimate seasonal 461 runoff volumes is assessed. From a risk management perspective, it is important to examine the 
462 accuracy of the tails of the forecast distributions, which may be used as maximum or minimum

463 expected flows. In order to assess the tails of the forecast distributions, the $99 \%, 95 \%$ and $90 \%$

464 predictive bounds from each method are examined, with their respective ERs, in Figure 4. This

465 figure suggests that every modeling scenario is overconfident at every predictive bound (each

466 predictive bound is exceeded at a frequency higher than optimal). At the $99 \%$ predictive bound,

467 each DA case reduces the overconfidence, highlighting the importance of initial condition

468 uncertainty, and PF-SBC further reduces the ER to about 3\%. This still remains slightly

469 overconfident, yet is a significant improvement over the other modeling cases (the best ESP-DA

470 case had $14.9 \%$ ER), thus highlighting the importance of accounting for model errors. At the

$47195 \%$ and $90 \%$ ERs, DA continues to improve overconfidence, with the exception of VIC with $\mathrm{T}_{\mathrm{b}}$

472 only DA, and PF-SBC again performs best overall. These results suggest that across the entire

473 basin, both ESP-DA and ESP-PF-SBC improve the reliability of the tails of the forecast

474 distributions, but gives no assessment of the performance spatially. In order to examine the

475 performance of the methods across several sub-basins, Figure 5 shows the 99\% ER of 16

476 different sub-basins within the UCRB.

477 The accuracy of the $99 \%$ predictive bounds varies spatially throughout the UCRB. In the

478 VIC open loop model, the San Juan is the only basin that has an ER of lower than 50\% (optimal

479 is $1 \%$ ), which shows that the probabilistic forecasts does not convey the proper uncertainty for

480 this model. In the DA cases, a reduction in the $99 \%$ ER is observed in every sub-basin outside of

481 the Colorado River headwater region. In this region, DA appears to struggle in improving the

482 accuracy of initial conditions, which is an observation that will be discussed further in relation to

483 later results. The NWS models perform much more consistently throughout the UCRB, with ERs

484 generally around 50\%, and greater variability in the Rocky Mountains. In the DA cases, the ER 
485 is reduced in all basins, suggesting generally more reliable forecasting of low probability events.

486 DA in these models appears to be more consistently effective than in VIC, which is attributed to

487 the differing spatial discretization, as mentioned in respect to model weights from Figure 3.

488 Finally, PF-SBC further reduces the ER, from which values are consistently below $10 \%$, with the

489 exception of the Dolores River Basin (southwestern sub-basin of the Colorado River headwater

490 region) at around 20\%. Overall this shows that DA tends to improve probabilistic prediction,

491 highlighting the importance of initial condition errors, and further improvements are made

492 through PF-SBC, showing the importance of the model error component. Though the results here

493 are encouraging, it is important to also look at the overall reliability of the forecast distributions

494 to ensure that reliability of the entire forecast distribution is improved. This is performed with the

$495 \quad R$ metric and is shown spatially in Figure 6.

496 In the VIC open loop case, reliability is low in the Green River Basin and in the Colorado

497 Headwaters, with better performance in the San Juan and at Lee's Ferry, which suggests a more

498 accurate reconstruction of initial states in the San Juan than the other sub-basins. In the two DA

499 cases, reliability is improyed in both the Green and San Juan basins, but the headwater basins

500 performs worse, similar to the results of the $99 \%$ ER. Both DA cases improved the initial

501 condition distribution in the Green and San Juan basins, yet struggled in the Colorado River

502 headwaters. In contrast to the VIC model, the NWS models have less variation in reliability, and

503 no identifiable pattern in performance. Also, the DA cases only show improvements in the San

504 Juan River basin, with slightly worse performance in many other basins. This observation is

505 unexpected in light of the improvements shown in figures 4 and 5. Such an observation suggests

506 that this method is unable to improve the central portions of the predictive distribution. Despite

507 an improvement in the tails for the forecast distributions from the DA cases, the mode of the 
508 distribution is not shifted enough to observe general improvements in reliability. Results from

509 the PF-SBC experiment show that the model averaging scenario is superior to all other cases in

510 the majority of basins, though exceptions are present in the upper Green river basin and central

511 Gunnison river basin (south-central portion of the Colorado River headwaters). The superior

512 results from PF-SBC over the entire forecast distribution, in conjunction with unimproved

513 reliability from DA, suggests that model errors are persistent in the central portion of the forecast

514 distribution. While the initial condition errors were important in estimating the low probability

515 events, it is essential to manage model error for accurate prediction of the mode of the forecast

516 distribution.

517 The conflicting results regionally, and within different portions of the forecast

518 distributions, requires further examination of the regional forecast distributions. The causes of

519 conflicting information from previous results are diagnosed with the predictive QQ plot from

520 each of the four gauges shown in Figure 1, which are provided in Figure 7. In the upper left plot

521 of Figure 7, it appears that both the NWS models and the VIC model have significant biases,

522 with the NWS models showing a generally high bias (observations primarily falling in the lower

523 portions of the forecast distributions) and the VIC model having a generally low bias

524 (observations primarily falling in the higher portions of the forecast distributions). In the NWS

525 models, DA does not change the bias, though it does move the tails of the distribution to

526 encompass more observations, but the VIC model has increasingly low bias with DA. These

527 differing results highlight the effects of spatial resolution on $\mathrm{T}_{\mathrm{b}} \mathrm{DA}$ in regions of highly complex

528 topography and thick vegetation. From Figure 1, it is apparent that the Colorado River

529 headwaters is the most topographically rough sub-basin and has the densest forest cover of all

530 regions, causing greater problems for DA in the VIC model. Since the NWS models are 
531 distributed based on topography, the basins in this region are much smaller than in the VIC

532 model, and thus the spatial heterogeneity is more effectively modeled. Conversely, in the Green

533 River, the bias in the VIC model was reduced through DA, but again only little change was

534 observed in the NWS bias in the DA case. In the San Juan, which has the lowest density of forest

535 cover and driest climate, the bias in both models is reduced, showing the ability of $\mathrm{T}_{\mathrm{b}} \mathrm{DA}$ to

536 reduce SWE errors in regions of thin vegetation and dry climates. With respect to the PF-SBC

537 case, the forecasts in the headwaters have a high bias, generally following the NWS model

538 forecasts, but in the Green and San Juan basins, PF-SBC provides a significant reduction in

539 model bias. In basins where both models provide sufficiently accurate forecasts, PF-SBC is

540 capable of effectively leveraging information from multiple model structures to improve

541 forecasts, but the poor forecasts from VIC in the headwaters forces PF-SBC to rely primarily on

542 the NWS modeling cases. Results at Lee's Ferry indicate the strong influence of the Colorado

543 River headwaters in flow at the outlet (on average it provides $45 \%$ of the runoff at Lee's Ferry),

544 which is unfortunate because forecasts for the headwaters are the least skillful, and show the

545 least sensitivity to the remotely sensed observations. Overall it appears that the tails of the

546 forecast distributions at Lee's Ferry are most accurate when using the ESP combined with PF-

547 SBC, but this framework is unable to provide much improvement in the mode of the forecast

548 distributions.

5495 Discussion and Conclusion

550 This study examined a number of modeling scenarios in attempts of improve the 551 characterization of errors in seasonal hydrologic forecasting. Based on the operational ESP

552 framework, the VIC and NWS models were used to generate probabilistic seasonal streamflow

553 forecasts. Each model had an open loop case, two DA cases ( $\mathrm{T}_{\mathrm{b}}$ only and $\mathrm{T}_{\mathrm{b}}$ with LST DA), and 
554 a model averaging case of all six prior scenarios was performed with PF-SBC. DA was

555 implemented to account for initial condition uncertainty, and PF-SBC is used to account for

556 uncertainty. Such an experiment is expected to improve the reliability of forecast distributions

557 from ESP, as ESP tends to produce overconfident results.

A first comparison of the modeling scenarios was provided with the relative performance

559 of each during the spin up period. During this time, the NWS models with $\mathrm{T}_{\mathrm{b}}$ only DA provided

560 the best overall probabilistic prediction, highlighting the effectiveness of the NWS forecasting

561 system, and the sensitivity of passive microwave $T_{b}$ to snowpack states. In addition, the relative

562 accuracy of the models with and without DA over the course of the accumulation and ablation

563 season highlights the temporal characteristics of $\mathrm{T}_{\mathrm{b}} \mathrm{DA}$ performance. In the accumulation

564 season, DA is more effective as the snow tends to be drier, but the open loop models perform

565 better in the ablation season as $\mathrm{T}_{\mathrm{b}}$ becomes less sensitive to SWE. Relative model weights also

566 suggest that VIC is more efficient in assimilating LST, which was expected as the VIC model

567 explicitly solves for LST, whereas the SNOW-17 model only estimates average pack

568 temperature.

569 Forecast reliability was shown to have a strong spatial component in figures 5 and 6 . The

570 VIC model produced forecasts with lower reliability than the NWS models, with the exception of

571 the San Juan basin, over the UCRB. Both VIC DA cases were capable of improving the forecast

572 reliability in the Green and San Juan basins, suggesting improvements in initial conditions, but

573 produced worse forecasts in the Colorado River headwaters. While the VIC model performed

574 worse with DA in the headwaters, the NWS models improved. This is counterintuitive as the

575 VIC model is expected to more accurately reconstruct the land surface states, but this result is

576 attributed to the coarser resolution of the VIC model, with respect to the NWS models in this 
577 region. In addition, DA in the NWS models provided the least improvement in this region, in

578 comparison to other regions, which highlights the difficulty of utilizing remotely sensed

579 information to reconstruct land surface states in regions of thick forest cover. This is unfortunate

580 as forest thickness is generally correlated with precipitation quantity, and thus more important

581 from a water supply perspective. Since the most densely forested region in a basin will tend to be

582 the most important from a water supply perspective, it is imperative that the accuracy of land

583 surface state estimation and observation, and therefore the combination of both through DA, be

584 improved in these regions, which is a great challenge for land surface hydrologist.

585 A final conclusion from this paper relates to the performance of different portions of the

586 forecast distributions. In general, the improvements were stronger in the tails of the distributions

587 than in the central portions, with the exception of the PF-SBC case in the Green and San Juan

588 basins. Since DA improved the tails of the distribution in nearly all basins/cases, yet did not

589 consistently improve total reliability, initial condition uncertainty is shown to have stronger

590 control over the reliability of predicting low probability events. Alternatively, PF-SBC improved

591 the overall reliability in nearly all basins, suggesting that model error strongly controls

592 uncertainty in the forecast distribution mode. Overall, this highlights that both initial condition

593 and model error are important factors in seasonal prediction.

594 The presented methodology shows promise for improving the reliability of seasonal

595 forecasting, by accounting for all sources of forecast uncertainty, but the results from the

596 application here clearly show room for improvement. It is suggested that these improvements

597 will come from advancements in land surface DA and improved multi-modeling to more

598 effectively manage forecast uncertainty. By developing more effective DA systems, the proposed

599 framework will have more accurate and reliable prediction of initial land surface conditions, 
600 which were shown to have significant contribution to probabilistic streamflow forecasting. In 601 addition, the inclusion of a greater variety of model structures will more effectively manage

602 model error, thus leading to more reliable forecast uncertainty quantification. Beyond simply 603 adding more models, the methodology may also benefit from more complex weighting schemes,

604 which focuses on different flow regimes (Georgakakos et al. 2004, Parrish et al., 2012) and 605 different forecast training window lengths (Parrish et al., 2012). A further advancement in 606 quantifying forecast uncertainty may also come from the use of state-parameter estimation within 607 the DA framework (DeChant and Moradkhani, 2012), which is becoming increasingly effective 608 and efficient (Moradkhani et al., 2012), and therefore more applicable to the spatial extents 609 considered here.

610

611 Acknowledgements

612 The authors would like to than the forecasters at the Colorado River Forecasting Center 613 for providing forcing and parameters for the NWS models. In addition, this study was supported 614 by NOAA-MAPP (NA110AR4310140).

615 


\section{References}

618 Ajami, N.K., Duan, Q. and Sorooshian, S., 2007. An integrated hydrologic Bayesian multimodel 619 combination framework: Confronting input, parameter, and model structural uncertainty in hydrologic prediction. Water Resources Research, 43(1): W01403.

Andreadis, K.M. and Lettenmaier, D.P., 2006. Assimilating remotely sensed snow observations into a macroscale hydrology model. Advances in Water Resources, 29(6): 872-886.

Andreadis, K.M. and Lettenmaier, D.P., 2012. Implications of Representing Snowpack Stratigraphy for the Assimilation of Passive Microwave Satellite Observations. Journal of Hydrometeorology, 13(5): 1493-1506.

Bohn, T.J., Sonessa, M.Y. and Lettenmaier, D.P., 2010. Seasonal hydrologic forecasting: Do multimodel ensemble averages always yield improvements in forecast skill? Journal of Hydrometeorology, 11(6): 1358-1372.

Bras, R. L. (1990), Hydrology: an introduction to hydrologic science, Addison-Wesley.

Brown, J.D., Demargne, J., Seo, D.-J., Liu, Y., 2010. The Ensemble Verification System (EVS): A software tool for verifying ensemble forecasts of hydrometeorological and hydrologic variables at discrete locations. Environmental Modelling \& Software, 25(7): 854-872.

Clark, M.P., Slater, A. G., Barrett, A. P., Hay, L. E., McCabe, G. J., Rajagopalan, B., Leavesley, G. H., 2006. Assimilation of snow covered area information into hydrologic and landsurface models. Advances in Water Resources, 29(8): 1209-1221.

636 Clark, M.P. et al., 2008. Hydrological data assimilation with the ensemble Kalman filter: Use of streamflow observations to update states in a distributed hydrological model. Advances in Water Resources, 31(10): 1309-1324. 
Day, G.N., 1985. Extended streamflow forecasting using NWSRFS. Journal of Water Resources Planning and Management, 111(2): 157-170.

644 Dechant, C. and Moradkhani, H., 2011a. Radiance data assimilation for operational snow and streamflow forecasting. Advances in Water Resources, 34(3): 351-364.

646 DeChant, C.M. and Moradkhani, H., 2011b. Improving the characterization of initial condition for ensemble streamflow prediction using data assimilation. Hydrology and Earth System Sciences Discussions, 8: 7207-7235.

DeChant, C.M. and Moradkhani, H., 2012. Examining the effectiveness and robustness of sequential data assimilation methods for quantification of uncertainty in hydrologic forecasting. Water Resources Research, 48(4): W04518.

De Lannoy, G.1.J.M. et al., 2012. Multiscale assimilation of Advanced Microwave Scanning Radiometer-EOS snow water equivalent and Moderate Resolution Imaging Spectroradiometer snow cover fraction observations in northern Colorado. Water Resources Research, 48(1).

De Lannoy, G.J.M., Reichle, R.H., Pauwels, V.R.N., 2013. Global Calibration of the GEOS-5 L-

Demargne, J. et al., 2013. The Science of NOAA's Operational Hydrologic Ensemble Forecast Service. Bulletin of the American meteorological Society.

Diks, C.G.H., Vrugt, J.A., 2010. Comparison of point forecast accuracy of model averaging methods in hydrologic applications. Stochastic Environmental Research and Risk Assessment, 24(6): 809-820.

Drusch, M., Wood, E.F. and Jackson, T.J., 2001. Vegetative and Atmospheric Corrections for the Southern Great Plains Hydrology Experiment 1997. Journal of Hydrometeorology, 2(2): 181-192. 
Using the Community Microwave Emission Model. Journal of Hydrometeorology, 10(1): 213-226.

672 Duan, Q., Ajami, N.K., Gao, X. and Sorooshian, S., 2007. Multi-model ensemble hydrologic prediction using Bayesian model averaging. Advances in Water Resources, 30(5): 13711386.

Durand, M. and Margulis, S.A., 2008. Effects of uncertainty magnitude and accuracy on assimilation of multiscale measurements for snowpack characterization. Journal of Geophysical Research, 113(D2): D02105.

Gao, H. et al., 2010. Water budget record from Variable Infiltration Capacity (VIC) model. Algorithm Theoretical Basis Document for Terrestrial Water Cycle Data Records.

Hersbach, H., 2000. Decomposition of the continuous ranked probability score for ensemble prediction systems. Weather and Forecasting, 15(5): 559-570.

Hsu, K.-1., Moradkhani, H. and Sorooshian, S., 2009. A sequential Bayesian approach for hydrologic model selection and prediction. Water Resources Research, 45(12): W00B12.

Jolliffe, I.T., Stephenson, D.B., 2003. Forecast Verification: A Practitioner's Guide in Atmospheric Science. Wiley. com.

Kalnay, E. et al., 1996. The NCEP/NCAR 40-year reanalysis project. Bulletin of the American meteorological Society, 77(3): 437-471.

691 Kimball, J. S., S. W. Running, and R. Nemani (1997), An improved method for estimating surface humidity from daily minimum temperature, Agricultural and Forest Meteorology, 85(1), 87-98.

694 Laio, F. and Tamea, S., 2007. Verification tools for probabilistic forecasts of continuous hydrological variables. Hydrology and Earth System Sciences, 11(4): 1267-1277. 
696

Leisenring, M. and Moradkhani, H., 2010. Snow Water Equivalent Estimation using Bayesian Data Assimilation Methods. Stochastic Environmental Research and Risk Assessment, : $1-18$.

Leisenring, M., Moradkhani, H., 2012. Analyzing the uncertainty of suspended sediment load prediction using sequential data assimilation. Journal of Hydrology, 468-469(0): 268282.

Li, H., Luo, L., Wood, E. F. and Schaake, J., 2009. The role of initial conditions and forcing uncertainties in seasonal hydrologic forecasting. Journal of Geophysical Research, 114(D4): D04114.

Li, D., Durand, M. and Margulis, S.A., 2012. Potential for hydrologic characterization of deep mountain snowpack via passive microwave remote sensing in the Kern River basin, Sierra Nevada, USA. Remote sensing of environment, 125(0): 34-48.

Liang, X., Lettenmaier, D.P., Wood, E.F. and Burges, S.J., 1994. A simple hydrologically based model of land surface water and energy fluxes for general circulation models. Journal of Geophysical Research: Atmospheres, 99(D7): 14415-14428.

Liu, Y. and Gupta, H.V., 2007. Uncertainty in hydrologic modeling: Toward an integrated data assimilation framework. Water Resources Research, 43(7): W07401.

Liu, Y., A.H. Weerts, M. Clark, H.J. Hendricks Franssen, S. Kumar, H. Moradkhani, D.J. Seo, D. Schwanenberg, P. Smith, A. I. J. M. van Dijk, N. van Velzen, M. He, H. Lee, S. J. Noh, O. Rakovec,, P. Restrepo, (2012), Toward Advancing Data Assimilation in Operational Hydrologic Forecasting and Water Resources Management: Current Status, Challenges, and Emerging Opportunities, Hydrol. Earth Syst. Sci., 16, 3863-3887.

Maurer, E. P., A. W. Wood, J. C. Adam, D. P. Lettenmaier, and B. Nijssen (2002), A Long-Term Hydrologically Based Dataset of Land Surface Fluxes and States for the Conterminous United States, Journal of Climate, 15(22), 3237-3251.

Madadgar, S., Moradkhani, H. and Garen, D., 2012. Towards improved post-processing of hydrologic forecast ensembles. Hydrological Processes, DOI: 10.1002/hyp.9562.

Margulis, S.A., McLaughlin, D., Entekhabi, D. and Dunne, S., 2002. Land data assimilation and estimation of soil moisture using measurements from the Southern Great Plains 1997 Field Experiment. Water Resources Research, 38(12): 1299. 
Mo, K.C., Shukla, S., Lettenmaier, D.P. and Chen, L.-C., 2013. Do Climate Forecast System (CFSv2) forecasts improve seasonal soil moisture prediction? Geophysical Research Letters, 39(23).

Montzka, C., H. Moradkhani, L. Weihermuller, M. Canty, H.J. Hendricks Franssen, and H. Vereecken, 2011. Hydraulic parameter estimation by remotely--sensed top soil moisture observations with the particle filter. Journal of Hydrology, 399(3-4): 410-421.

Montzka, C., J. Grant, H. Moradkhani, H.J., Hendricks Franssen, L. Weihermüller, M. Drusch, and H. Vereecken (2013), Estimation of radiative transfer parameters from L-Band passive microwave brightness temperatures using data assimilation, Vadose Zone Hydrology, Special Issue of Remote Sensing, doi:102136/vzj2012.0040.

Moradkhani, H., Sorooshian, S., Gupta, H.V., Houser, P.R., 2005a. Dual state-parameter estimation of hydrological models using ensemble Kalman filter. Advances in Water Resources, 28(2): 135-147.

Moradkhani, H., Hsu, K. L., Gupta, H. and Sorooshian, S., 2005b. Uncertainty assessment of hydrologic model states and parameters: Sequential data assimilation using the particle filter. Water Resources Research, 41(5): W05012.

Moradkhani, H., K. Hsu, Y. Hong and S. Sorooshian (2006), Investigating the Impact of Remotely Sensed Precipitation and Hydrologic Model Uncertainties on the Ensemble Streamflow Forecasting, Geophys. Res. Lett., Vol. 33, No. 12, L12401, 10.1029/2006GL026855.

Moradkhani, H. and S. Sorooshian (2008), General Review of Rainfall-Runoff Modeling: Model Calibration, Data Assimilation, and Uncertainty Analysis, in Hydrological Modeling and Water Cycle, Coupling of the Atmospheric and Hydrological Models, Springer, Water Science and Technology Library, volume 63, Part 1, 1-24, DOI: 10.1007/978-3-54077843-1-1.

Moradkhani, H. (2008), Hydrologic Remote Sensing and Land Surface Data Assimilation, Sensors, 8, 2986-3004; DOI: 10.3390/s8052986.

Moradkhani, H., and T. Meskele (2009), Probabilistic Assessment of the Satellite Rainfall Retrieval Error Translation to Hydrologic Response, in Satellite Applications for Surface Hydrology, Springer, Water Science and Technology Library, DOI 10.1007/978-90-481-2915-7, pp 229-242 
Moradkhani, H., M. Meier, (2010), Long-Lead Water Supply Forecast using Large-scale Climate Predictors and Independent Component Analysis, J. of Hydrologic Engineering, 15(10), 744-762.

Moradkhani, H., C. M. DeChant, and S. Sorooshian (2012), Evolution of ensemble data assimilation for uncertainty quantification using the particle filter-Markov chain Monte Carlo method, Water Resources Research, 48(12), W12520.

Murphy, A.H., 1973. A New Vector Partition of the Probability Score. Journal of Applied Meteorology, 12(4): 595-600.

Najafi, M.R., Moradkhani, H. and Piechota, T.C., 2012. Ensemble Streamflow Prediction: Climate signal weighting methods vs. Climate Forecast System Reanalysis. Journal of Hydrology, 442-443(0): 105-116.

Parrish, M.A., Moradkhani, H. and DeChant, C.M., 2012. Toward reduction of model uncertainty: Integration of Bayesian model averaging and data assimilation. Water Resources Research, 48(3): W03519.

Pulliainen, J. et al., 1998. Retrieval of Geophysical Parameters with Integrated Modeling of Land Surfaces and Atmosphere (models/inversion Algorithms): Final Report. Helsinki University of Technology, Laboratory of Space Technology.

Raftery, A.E., Gneiting, T., Balabdaoui, F. and Polakowski, M., 2005. Using Bayesian Model Averaging to Calibrate Forecast Ensembles. Monthly Weather Review, 133(5): 11551174.

Regonda, S.K., Rajagopalan, B., Clark, M. and Zagona, E., 2006. A multimodel ensemble forecast framework: Application to spring seasonal flows in the Gunnison River Basin. Water Resources Research, 42(9): W09404.

Reichle, R.H., McLaughlin, D.B. and Entekhabi, D., 2002. Hydrologic data assimilation with the ensemble Kalman filter. Monthly Weather Review, 130: 103-114.

Sabater, J.M., De Rosnay, P., Balsamo, G., 2011. Sensitivity of L-band NWP forward modelling to soil roughness. International Journal of Remote Sensing, 32(19): 5607-5620. 
Shukla, S., Sheffield, J., Wood, E.F. and Lettenmaier, D.P., 2013. On the sources of global land surface hydrologic predictability. Hydrology and Earth System Sciences Discussions, 10(2): 1987-2013.

Thornton, P. E., and S. W. Running (1999), An improved algorithm for estimating incident daily solar radiation from measurements of temperature, humidity, and precipitation, Agricultural and Forest Meteorology, 93(4), 211-228.

Twedt, T.M., Schaake Jr, J.C., and Peck, E.L.: National Weather Service extended streamflow prediction. in Proc. 45th Western Snow Conference. Albuquerque, NM, Colorado State University, 52-57.1977

U.S. Department of the Interior (2005), Natural flow and salt computation methods, Bur. of Reclam., Salt Lake City, Utah.

Wan, Z. and Dozier, J., 1996. A generalized split-window algorithm for retrieving land-surface temperature from space. Geoscience and Remote Sensing, IEEE Transactions on, 34(4): 892-905.

Wan, Z.Z., Y. Zhang, Q. Li, Z. L., 2004. Quality assessment and validation of the MODIS global land surface temperature. International Journal of Remote Sensing, 25(1): 261-274.

Wiesmann, A. and Mätzler, C., 1999. Microwave emission model of layered snowpacks. Remote sensing of environment, 70(3): 307-316.

Wigneron, J.P. et al., 2007. L-band Microwave Emission of the Biosphere (L-MEB) Model: Description and calibration against experimental data sets over crop fields. Remote sensing of environment, 107(4): 639-655.

Wilks, D.S., 2006. Statistical methods in the atmospheric sciences : an introduction. International geophysics series. Academic, Oxford, xvii, 627 p. pp.

Wood, A.W. and Lettenmaier, D.P., 2008. An ensemble approach for attribution of hydrologic prediction uncertainty. Geophysical Research Letters, 35(14): L14401.

Yossef, N.C., Winsemius, H., Weerts, A., van Beek, R., Bierkens, M.F.P., 2013. Skill of a global seasonal streamflow forecasting system, relative roles of initial conditions and meteorological forcing. Water Resources Research, 49(8): 4687-4699. 
810 Yuan, X. and Wood, E.F., 2012. Downscaling precipitation or bias-correcting streamflow? Some 811 implications for coupled general circulation model (CGCM)-based ensemble seasonal 812 hydrologic forecast. Water Resources Research, 48(12): W12519.

813 Yuan, X., Wood, E.F., Roundy, J.K. and Pan, M., 2013. CFSv2-based seasonal hydroclimatic 814 forecasts over conterminous United States. Journal of Climate (2013).

815 


\section{Upper Colorado River Basin}

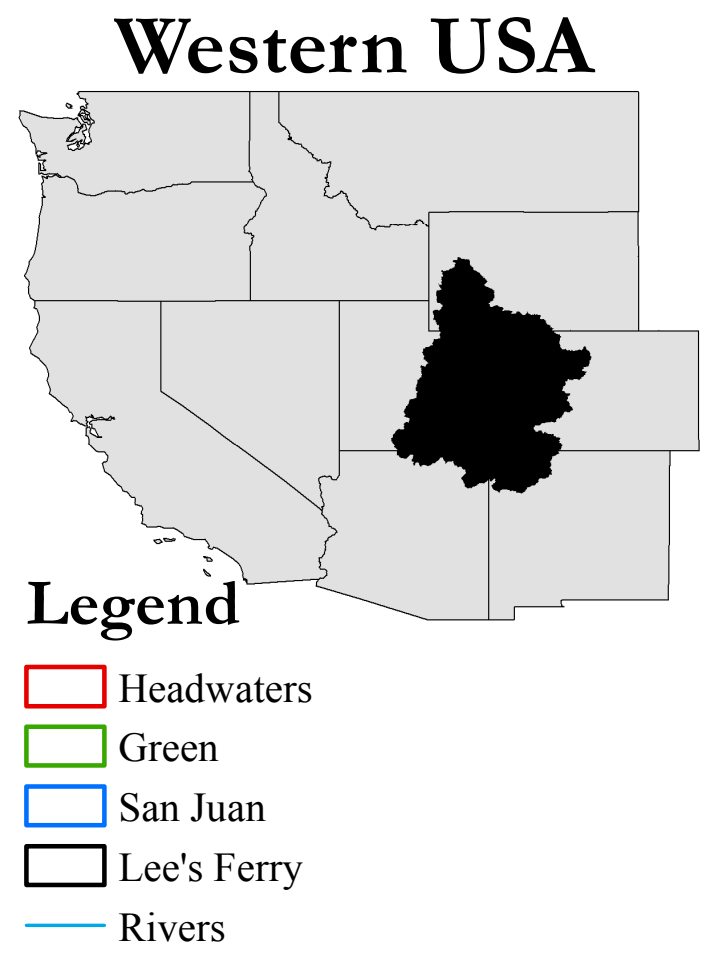

Vegetation Type
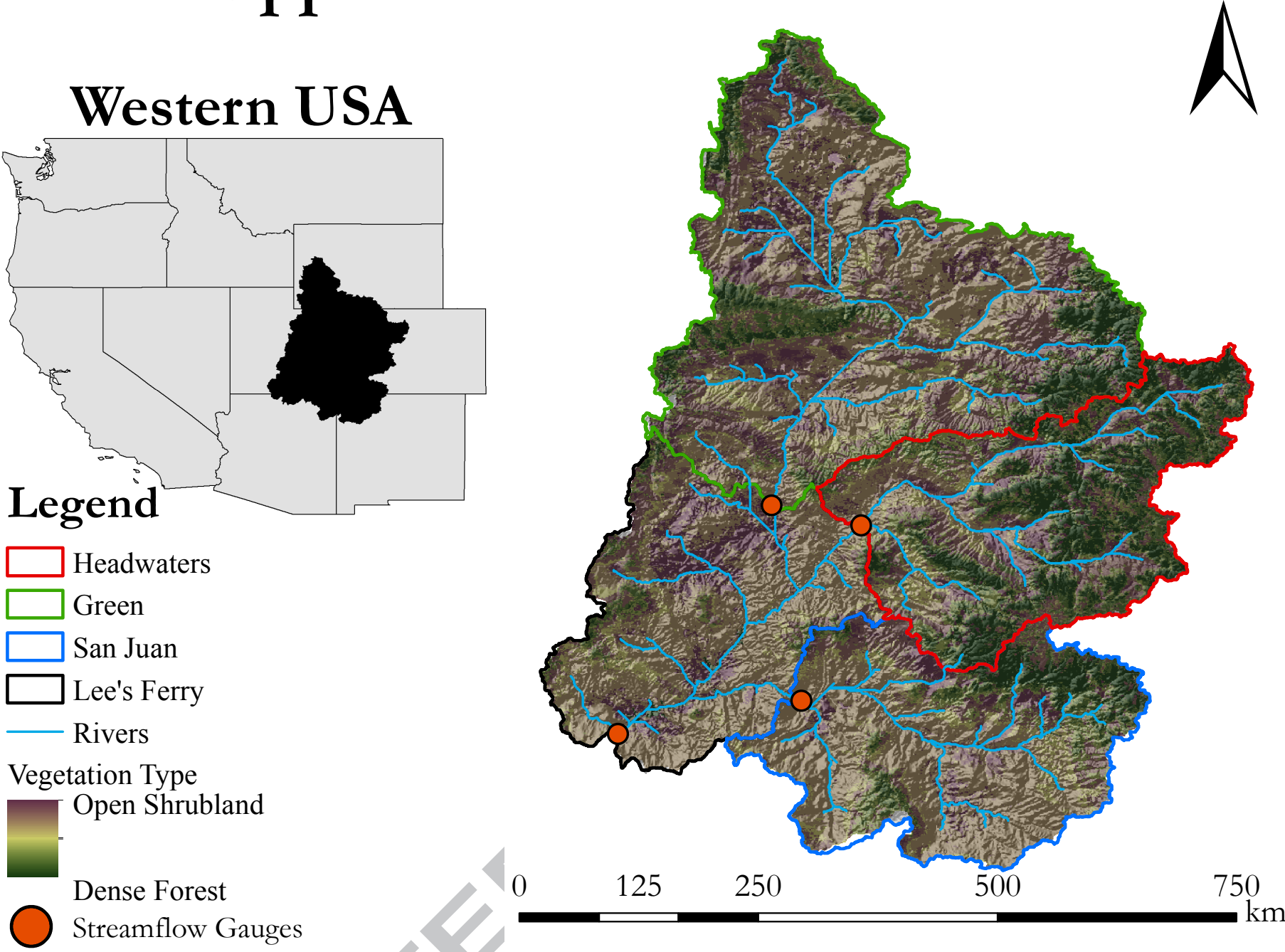

Figure 1. Map of the upper Colorado River Basin, with major sub-basins highlighted, and vegetation density overlying shaded relief. 


\section{ACCEPTED MANUSCRIPT}

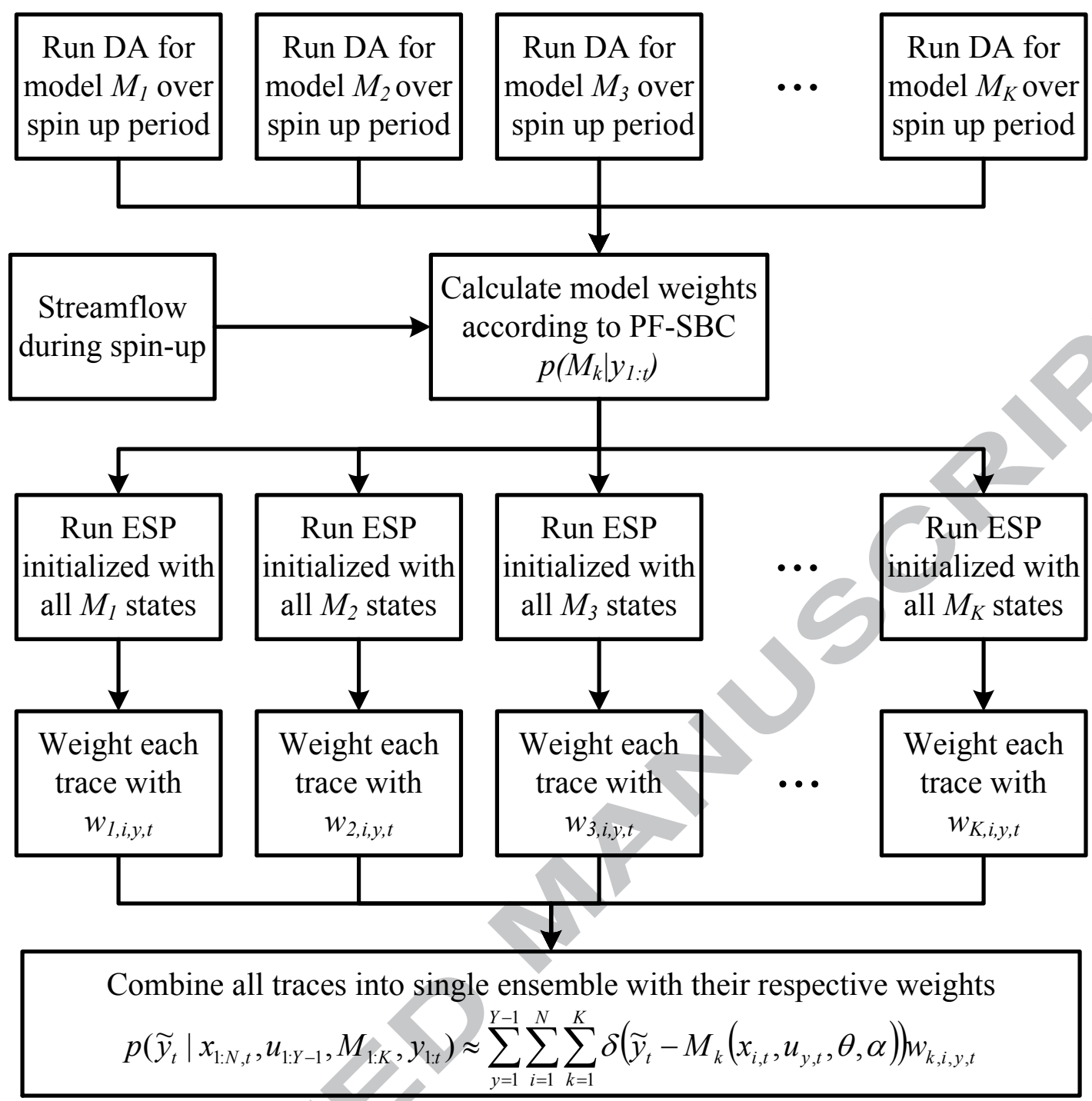

Figure 2. Flowchart describing the application of the PF-SBC algorithm to streamflow forecasting with ESP. 


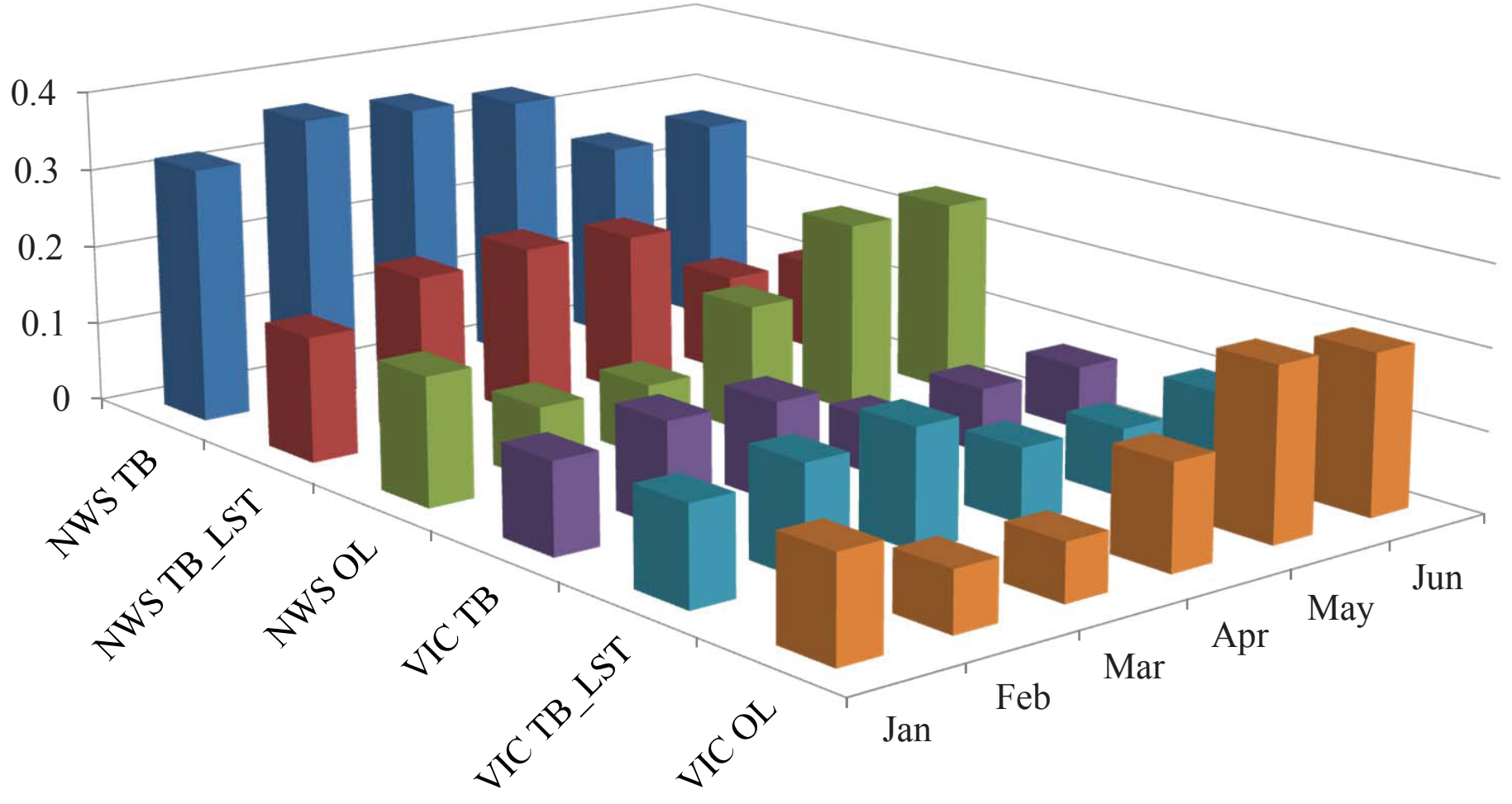

Figure 3. 3-dimensional bar plot of the average weights for each modeling scenario and forecast month, as estimated during the spin-up period. 


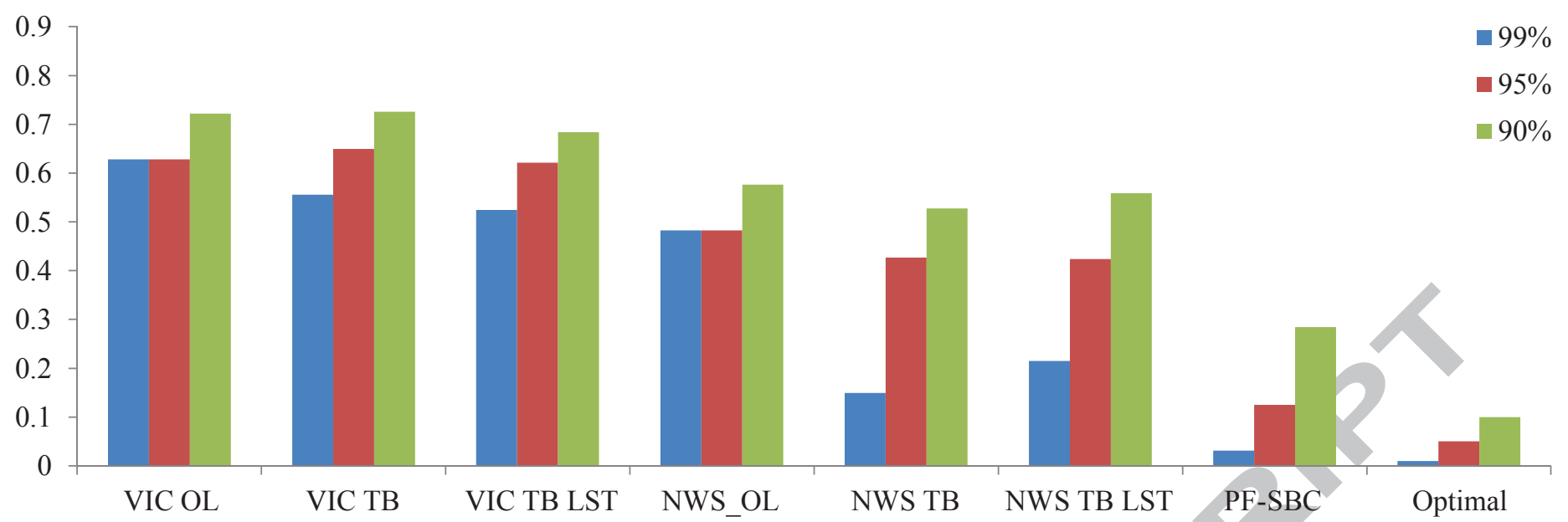

Figure 4. Histogram of the $99 \%, 95 \%$ and $90 \%$ exceedance ratios of each modeling scenario, for all seasonal forecasting experiments. The optimal exceedance ratio is on the far right of this figure. 


\section{ACCEPTED MANUSCRIPT}
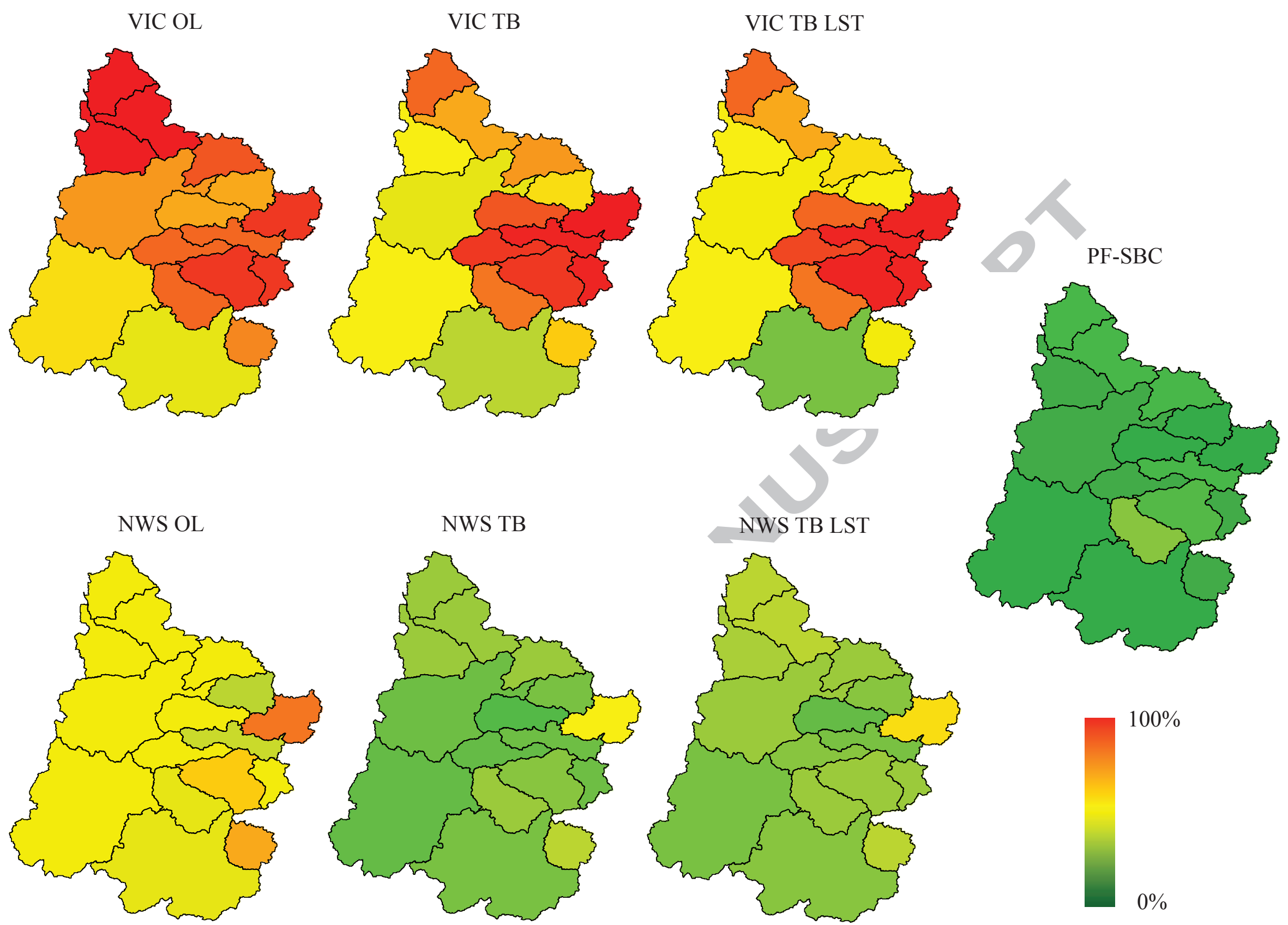

Figure 5. 99\% exceedance ratio over 16 sub-basins within the upper Colorado River Basin, for all volumetric streamflow forecasts. 


\section{ACCEPTED MANUSCRIPT}
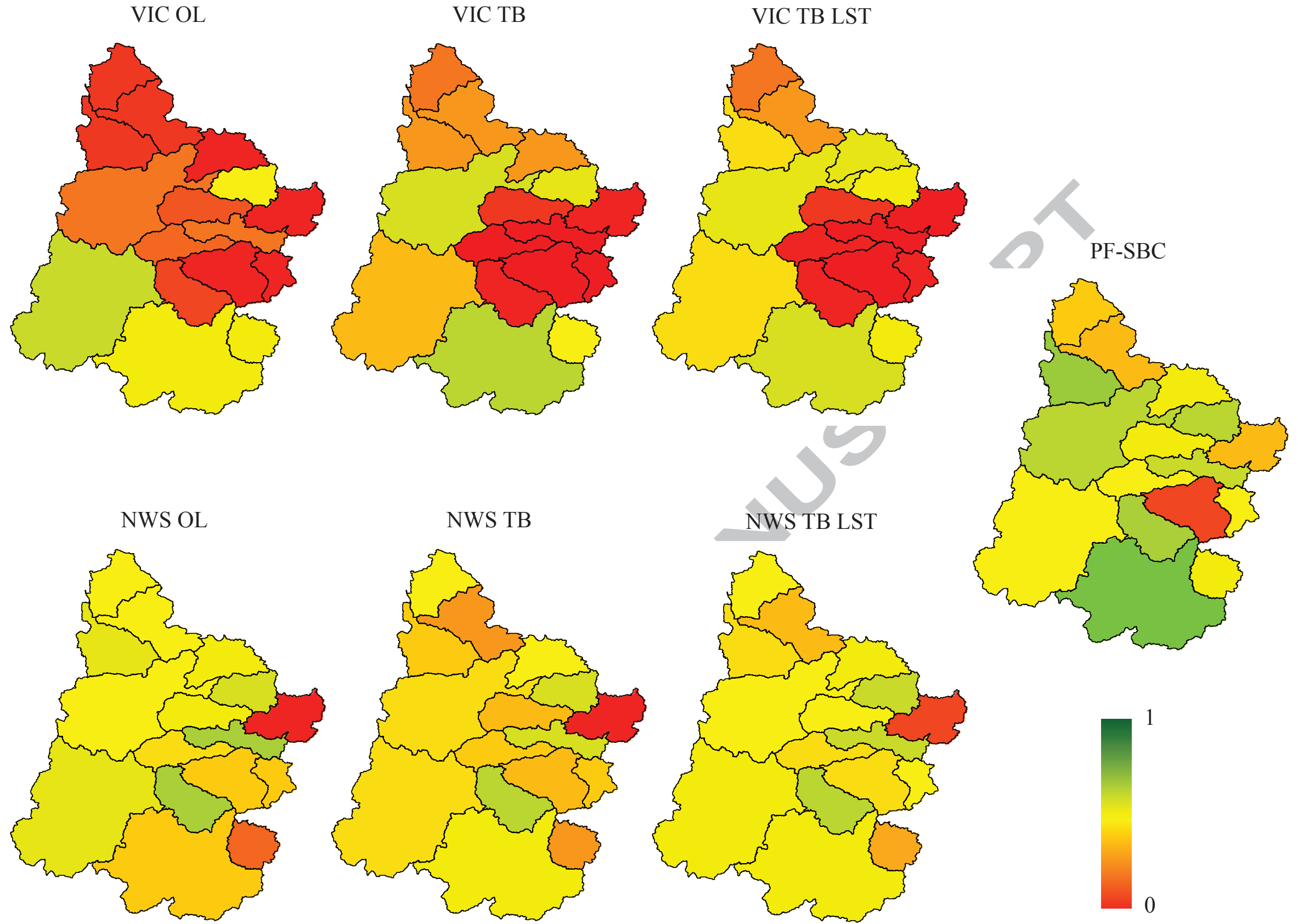

Figure 6. Reliability over 16 sub-basins within the upper Colorado River Basin, for all volumetric streamflow forecasts. 


\section{ACCEPTED MANUSCRIPT}
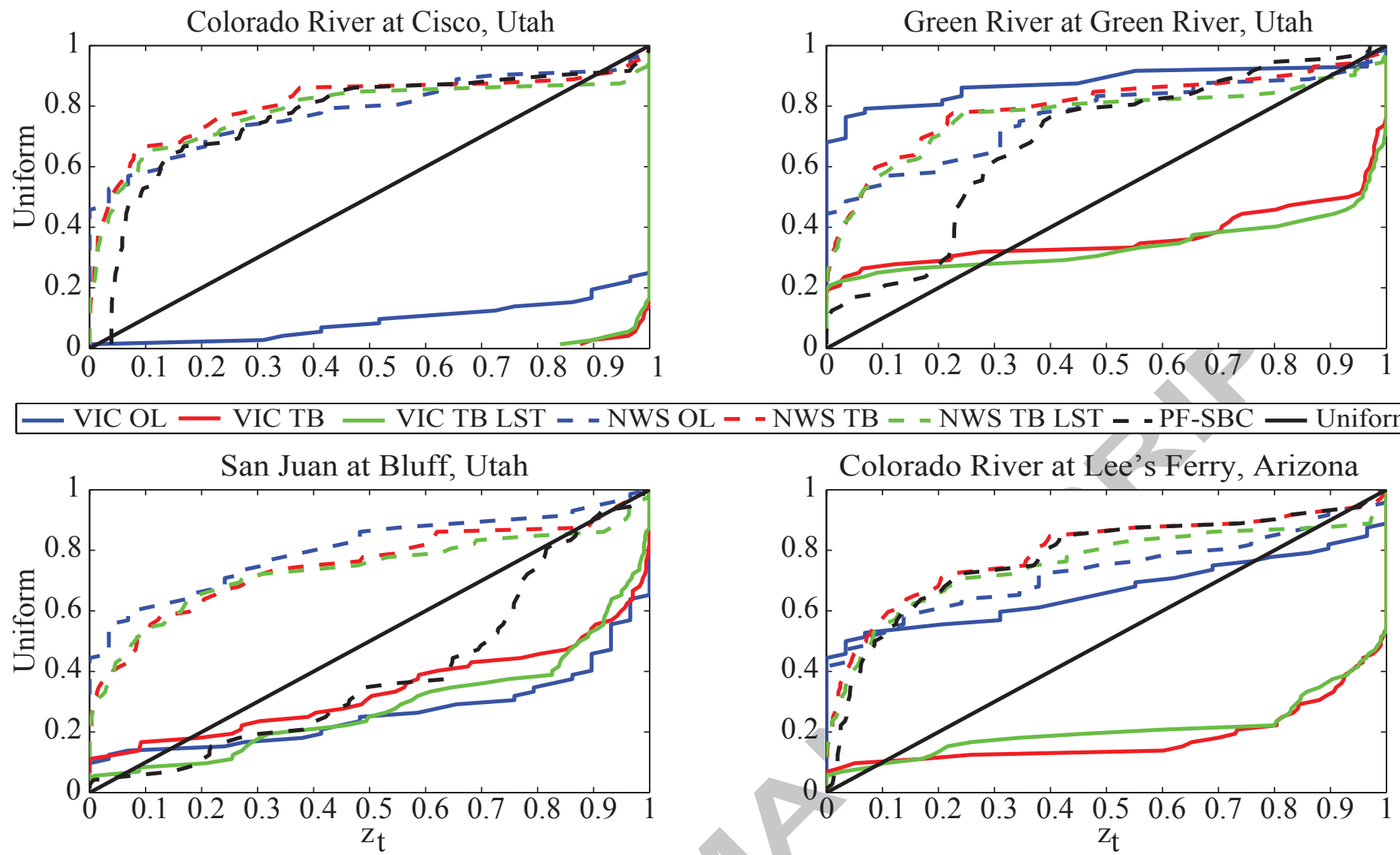

Figure 7. Predictive QQ plot of the volumetric seasonal forecasts from the four major sub-basins of the upper Colorado River Basin. 


\section{Highlights}

817 - Data Assimilation and Sequential Bayesian Combination reduces overconfidence in ESP

818 - Initial condition uncertainties have strongest effects on the tails of the forecast

819 distribution

820 - Model structural errors have strongest effect on the medial portions of the forecast

$821 \quad$ distribution

822 - Data Assimilation appears to be necessary to maximize the reliability of seasonal

823 forecasts

824

825

826 